\title{
Faktor Risiko Host terhadap Kejadian Schistosomiasis Japonicum
}

\section{Risk Factor of Host to Schistosomiasis Japonicum}

\begin{tabular}{c}
\hline Dian Muslimin \\
\hline STIkes Husada Mandiri Poso \\
e-mail: Dianmuslimin87@gmail.com
\end{tabular}

\begin{abstract}
Abstrak
Schistosomiasis japonicum dianggap suatu penyakit kemiskinan yang mengarah ke gangguan kesehatan kronis. Infeksi terjadi ketika manusia kontak dengan air tawar yang mengandung serkaria dari cacing parasit darah. Penelitian ini bertujuan untuk menjelaskan berbagai faktor Host yang merupakan faktor risiko terhadap kejadian Schistosomiasis japonicum. Metode Penelitian ini menggunakan mix method dengan kuantitatif sebagai pendekatan utama (case control) dan kualitatif sebagai pendukung (indepth interview). Populasi target adalah seluruh penduduk yang melakukan pemeriksaan tinja di laboratorium Schistosomiasis japonicum dan berdomisili di Taman Nasional Lore-Lindu Kabupaten Sigi Provinsi Sulawesi Tengah tahun 2014-2016 dengan jumlah sampel 158 orang terdiri dari 79 kasus dan 79 kontrol dengan teknik consecutive sampling. Analisis data bertahap dari univariat dan bivariat menggunakan uji chi-square dilanjutkan analisis multivariat menggunakan uji regresi logistik. Hasil Faktor Host yang terbukti sebagai risiko terhadap kejadian Schistosomiasis japonicum yaitu pekerjaan sebagai petani $\mathrm{OR}=2,8 ; 95 \% \mathrm{Cl}=1,22-6,48)$, kebiasaan mandi/mencuci di air sungai/danau $\mathrm{OR}=2,7 ; 95 \% \mathrm{Cl}=1,21$ 6,39 ), kebiasaan buang air besar selain di jamban $O R=3,0$; $95 \% \mathrm{Cl}=1,36-6,86)$, tidak menggunakan sepatu boot $\mathrm{OR}=4,6$; $95 \% \mathrm{Cl}=1,99-10,58)$, melewati daerah fokus keong $\mathrm{OR}=3,1$; $95 \% \mathrm{Cl}=1,34-7,41)$, memiliki tata guna lahan pertanian tidak dikelolah $\mathrm{OR}=5,2 ; 95 \% \mathrm{Cl}=2,25-12,00)$. Sedangkan faktor tidak terbukti sebagai faktor risiko yaitu tingkat pendidikan rendah <SMP, tidak pemanfaatan sumber air bersih, menjadi anggota mapalus, tidak memanfaatkan program kesehatan, dan memelihara hewan ternak. Probabilitas untuk menyebabkan kejadian Schistosomiasis japonicum terdapat enam faktor risiko sebesar $98,52 \%$.
\end{abstract}

Kata Kunci : Faktor Risiko, Kejadian Schistosomiasis Japonicum, Taman Nasional Lore-Lindu.

\section{Abstrack}

Background: Schistosomiasis japonicum was considered a disease of poverty that leads to chronic health problems.
Schistosomiasis japonicum infection occurs when people ware closely associated with frequencies of water contact that contain serkaria parasite worms blood. There the aim of this study was to describe host and environment are the risk factor for incidence of Schistosomiasis japonicum. Methods The research applied with mix method ware quantitative as the main approach case control design) and qualitative as support (indepth interview). Target population is all people who conduct the examination in the laboratory Schistosomiasis japonicum and domiciled in the national in Lore-Lindu National Park, Sigi District Central Sulawesi Province year 2014 to 2015 there ware 158 respondent involved, consisting of 79 case and 79 controls with consecutive sampling technique. Data analysis included univariat and bivariate analyzed using the chi square test and multivariate analysis logistic regression test. Results Host factor has proved be a risk factor to Schistosomiasis japonicum. The farmers $\mathrm{OR}=2,8 ; 95 \% \mathrm{Cl}=1,22$ to 6,48$)$, taking baths/washing in a rivers or lakes $O R=2,7 ; 95 \% \mathrm{Cl}=$ 1,21 to 6,39 , not to defecate in toilet $O R=3,0 ; 95 \% \mathrm{Cl}=1,36$ to 6,86 , not using boot $O R=4,6 ; 95 \% \mathrm{Cl}=1,99$ to 10,58 , trough the snail focus area $O R=3,195 \% \mathrm{Cl}=1,34$ to 7,41$)$, has agricultural land use $O R=5,295 \% \mathrm{Cl}=2,25$ to 12,00$)$. The factors ware not proved be a risk factor is the level of health programs, and has livestock animal. There are six risk factor amount $98,52 \%$, probability of Schistosomiasis japonicum.

Key word: Risk Factors, Schistosomiasis Japonicum, LoreLindu National Park, Sigi District Central Sulawesi Province.

\section{Pendahuluan}

Schistosomiasis ialah penyakit parasitik akut dan kronik yang disebebkan oleh cacing trematoda darah yang menyebabkan demam, fibrosis periportal dalam hati, sirosis hati, hipertensi portal adanya bendungan empedu dalam saluran hati, splenomegali dan acites. ${ }^{1-3}$ Schistosomiasis tergolong dalam, class trematoda, genus Schistosoma dan dari spesies Schistosomiasis japonicum. ${ }^{2}$ Di Indonesia Schistosomiasis disebabkan oleh Schistosomiasis japonicum ditemukan 
endemik di tiga daerah di Sulawesi Tengah, yaitu di Taman Nasional Lore-Lindu dan Dataran Tinggi Napu dan Bada, Hospes perantaranya yaitu keong Oncomelania hupensisi linduensis. Penyakit ini merupakan penyakit zoonosis sehingga sumber penularannya tidak sebatas pada penderita manusia saja, tapi semua hewan mamalia yang terinfeksi. ${ }^{4}$

Schistosomiasis japonicum dianggap suatu penyakit kemiskinan yang mengarah ke gangguan kesehatan kronis. Infeksi terjadi ketika manusia kontak dengan air tawar yang mengandung serkaria dari cacing parasit darah. Infeksi Schistosomiasis sering terjadi di daerah tropis maupun di daerah sub-tropis, masih banyak ditemukan di masyarakat yang tidak memiliki air minum dan sanitasi yang tidak memadai. ${ }^{5,6}$

Di Taman Nasional Lore-Lindu, prevalensi Schistosomiasis japonicum pada manusia selama 5 tahun terakhir 2010-2015 yaitu berturut-turut $5,3 \%, 1,2 \%, 1,8 \%, 2.61 \%$, $2,43 \%, 3,30 \%$. Di Taman Nasional Lore-Lindu Kabupaten Sigi semakin menurun setelah dilakukan program pengobatan secara efektif. Meskipun demikian, beberapa Desa masih memiliki prevalensi yang cukup tinggi setiap tahunnya. Berdasarkan data terakhir tahun 2015 Desa yang terdapat di Taman Nasional Lore-Lindu prevalensi masih di atas $1 \%$, menunjukkan prevalensi Desa Langko 1,91\%, Tomado 1,88\%, Puroo 1,54\%, Anca $1,11 \%$ dan Desa Salutui 1,04\%.,

Secara epidemiologi penularan Schistosomiasis japonicum tidak terpisah dari faktor perilaku atau kebiasaan yang tidak terpisahkan dari air yang terinfeksi parasit Schistosoma. ${ }^{9}$ Kejadian Schistosomiasis japonicum diduga kuat karena faktor Host. Oleh sebab itu sagat perlu dilakukan penelitian untuk mengetahui dan membuktikan faktor risiko Host terhadap kejadian Schistosomiasis japonicum, dalam upaya memantau peningkatan kasus, juga untuk memahami penanggulangan dan pencegahan yang tepat.

\section{Metode Penelitian}

Desain penelitian ini adalah analitik observasional dengan desain case-control, yang bertujuan untuk menilai hubungan paparan dan penyakit dengan cara menentukan kelompok kasus dan kelompok kontrol, lalu membandingkan frekuensi paparan atau level paparan pada kedua kelompok tersebut untuk menentukan faktor risiko apa yang membedakan keduanya terhadap kejadian Schistosomiasis japonicum. ${ }^{10,11}$ Populasi studi yaitu seluruh penduduk yang berdomisili di Taman Nasional Lore-Lindu, yang pernah memeriksakan tinja di laboratorium (periode Januari 2014 - Mei 2016) yang memenuhi kriteria inklusi dan eksklusi.

Teknik Pengambilan sampel kelompok kasus dengan cara consecutive sampling. Yaitu pengambilan sampel kelompok kasus berdasarkan urutan data rekam medis dari laboratorium Schistosomiasis dan memenuhi kriteria lnklusi yaitu menderita Schistosomiasis, memiliki catatan rekam medis yang lengkap, bersedia menjadi responden pada periode 2014- Mei 2016. Pengambilan sampel kelompok kontrol dengan cara Neighbourhood, kontrol diambil dari tetangga atau Desa yang sama dengan kelompok kasus periode tahun 2014 - Mei 2016, yang memenuhi kriteria inklusi dan eksklusi. Sampel minimum yang digunakan yaitu 79 subjek kasus dan 79 subjek kontrol. Penelitian ini menggunakan perbandingan 1:1, maka perbandingan subjek kasus dan kontrol adalah 79:79. Sehingga jumlah keseluruhan subjek yang memungkinkan pada penelitian ini adalah 158 orang.

Kejadian Schistosomiasis japonicum merupakan variabel terikat pada penelitian ini, sedangkan variabel bebas meliputi tingkat pendidikan, jenis pekerjaan, kebiasaan 
mandi/mencuci, pemanfaatan jamban, pemanfaatan sumber air bersih, penggunaan alat pelindung diri sepatu jenggel boot, melewati daerah fokus keong, menjadi anggota dalam budaya mapalus menanam padi, pemanfaatan program kesehatan, memilihara hewan ternak, dan memiliki tata guna lahan pertanian. Analisis secara bivariat dengan uji statistik chi square digunakan untuk menganalisis semua variabel yang di teliti dan analisis multivariat dengan uji regresi logistik.

\section{Hasil Penelitian}

\section{Analisis Bivariat}

Analisis bivariat untuk mengetahui hubungan antara variabel independen dengan kejadian Schistosomiasis japonicum (variabel dependen), dengan tingkat kemaknaan 95\%. Secara lengkap. Distribusi faktor yang berhubungan dengan kejadian Schistosomiasis japonicum dapat dilihat pada tabel dibawah ini:

Tabel.1. Ringkasan analisis bivariat

\begin{tabular}{|c|c|c|c|c|c|}
\hline \multirow[t]{2}{*}{ Variabel } & \multicolumn{2}{|c|}{ Schistosomiasis Japonicum } & \multirow[t]{2}{*}{ OR } & \multirow[t]{2}{*}{ 95\% CI } & \multirow[t]{2}{*}{$P$} \\
\hline & Kasus n (\%) & Kontrol n (\%) & & & \\
\hline \multicolumn{6}{|l|}{ Tingkat pendidikan } \\
\hline - Rendah $<$ SMP & $48(60,8)$ & $45(57,0)$ & 1,1 & $0,62-2,20$ & 0,628 \\
\hline - Tinggi $\geq$ SMP & $31(39,2)$ & $34(43,0)$ & & & \\
\hline \multicolumn{6}{|l|}{ Pekerjaan } \\
\hline - Tani & $56(70,9)$ & $42(53,2)$ & 2,1 & $1,11-4,13$ & 0,022 \\
\hline - Bukan Tani & $23(29,1)$ & $37(46,8)$ & & & \\
\hline \multicolumn{6}{|l|}{ Kebiasaan mandi/mencuci } \\
\hline - Air sungai/danau & $45(57,0)$ & $30(38,0)$ & 2,1 & $1,14-4,08$ & 0,017 \\
\hline - Air perpipaan & $34(43,0)$ & $49(62,0)$ & & & \\
\hline \multicolumn{6}{|l|}{ Perilaku buang air besar } \\
\hline - Sungai/danau & $51(64,6)$ & $26(32,9)$ & 3,7 & $1,92-7,16$ & 1,001 \\
\hline - Jamban & $28(35,4)$ & $53(67,1)$ & & & \\
\hline \multicolumn{6}{|l|}{ Pemanfaatan sumber air bersih } \\
\hline - Sumur,sungai dan danau & $37(46,8)$ & $24(30,4)$ & 2,0 & $1,05-3,87$ & 1,034 \\
\hline - Perpipaan/PDAM & $42(53,2)$ & $55(69,6)$ & & & \\
\hline \multicolumn{6}{|l|}{ Penggunaan sepatu jenggel boot } \\
\hline - Tidak menggunakan & $48(60,8)$ & $22(27,8)$ & 4,0 & $2,05-7,82$ & 0,001 \\
\hline - Menggunakan & $31(39,2)$ & $57(72,2)$ & & & \\
\hline \multicolumn{6}{|l|}{ Melewati daerah fokus keong } \\
\hline - Melewati & $37(46,8)$ & $17(21,5)$ & 3,2 & $1,60-6,43$ & 0,001 \\
\hline - Tidak melewati & $42(53,2)$ & $62(78,5)$ & & & \\
\hline \multicolumn{6}{|l|}{ Menjadi anggota mapalus } \\
\hline - Anggota mapalus & $45(57,0)$ & $26(32,9)$ & 2,6 & $1,41-5,15$ & 0,002 \\
\hline - Tidak anggota mapalus & $34(43,0)$ & $53(67,1)$ & & & \\
\hline \multicolumn{6}{|c|}{ Memanfaatkan program kesehatan } \\
\hline - Tidak memanfaatkan & $18(22,8)$ & $6(7,6)$ & 3,5 & $1,34-9,60$ & 0,008 \\
\hline - Memanfaatkan & $61(77,2)$ & $73(92,4)$ & & & \\
\hline \multicolumn{6}{|l|}{ Memelihara hewan ternak } \\
\hline - Memelihara & $38(48,1)$ & $24(30,4)$ & 2,1 & $1,10-4,07$ & 0,023 \\
\hline - Tidak memelihara & $41(51,9)$ & $55(69,6)$ & & & \\
\hline \multicolumn{6}{|c|}{$\begin{array}{l}\text { Memiliki lahan pertanian tidak diolah } \\
\text { - Memiliki }\end{array}$} \\
\hline _ Tidak memiliki & $46(58,2)$ & $17(21,5)$ & 5,0 & $2,52-10,22$ & 0,001 \\
\hline & $33(41,8)$ & $62(78,5)$ & & & \\
\hline
\end{tabular}


Tabel 1 menunjukan bahwa variabel yang secara statistik berhubungan dengan kejadian Schistosomiasis japonicum adalah pekerjaan sebagai petani, kebiasaan mandi mencuci, perilaku buang air besar, pemanfaatan sumber air bersih, penggunaan alat pelindung diri sepatu jenggel boot, melewati daerah fokus keong, menjadi anggota mapalus menanam padi, pemanfaatan program kesehatan, memelihara hewan ternak, memiliki lahan pertanian tidak diolah.Variabel yang menjadi kandidat dalam uji regresi logistik ini adalah variabel yang dalam analisis bivariat mempunyai nilai $\mathrm{p}<0,25$ yaitu pekerjaan sebagai petani, kebiasaan mandi mencuci, perilaku buang air besar, pemanfaatan sumber air bersih, penggunaan alat pelindung diri sepatu jenggel boot, melewati daerah fokus keong, menjadi anggota mapalus menanam padi, pemanfaatan program kesehatan, memelihara hewan ternak, memiliki lahan pertanian tidak diolah.

Untuk analisis multivariat selengkapnya dapat dilihat pada tabel berikut:

\section{Analisis Multivariat}

Tabel 2. Hasil Analisis Uji Regresi Logistik

\begin{tabular}{llcccc}
\hline \multicolumn{1}{c}{ Faktor Risiko } & Nilai B & OR & 95\% CI & P \\
\hline 1 & Pekerjaan sebagai petani & 1,03 & 2,8 & $1,22-6,48$ & 0,015 \\
2 & Kebiasaan mandi mencuci di air sungai dan air danau & 1,02 & 2,7 & $1,21-6,39$ & 0,016 \\
3 & Tidak buang air besar di jamban & 1,11 & 3,0 & $1,36-6,86$ & 0,007 \\
4 & Tidak menggunakan APD sepatu jenggel boot & 1,52 & 4,6 & $1,99-10,58$ & 0,001 \\
5 & Melewati daerah fokus & 1,15 & 3,1 & $1,34-7,41$ & 0,008 \\
6 & Memiliki lahan pertanian tidak diolah & 1,65 & 5,2 & $2,25-12,00$ & 0,001 \\
\hline
\end{tabular}

\section{Pembahasan}

Hasil analisis multivariat menunjukkan bahwa faktor Host yang membuktikan sebagai faktor risiko kejadian Schistosomiasis japonicum adalah pekerjaan sebagai petani merupakan pekerjaan yang berkaitan dengan kejadian Schistosomiasis japonicum yaitu pekerjaan yang dilakukan di sawah atau kebun, pekerjaan tersebut sering berhubungan dengan air, dimana diketahui bahwa mekanisme penularan serkaria parasit Schistosomiasis sangat erat kaitanya dengan air sungai sebagai media penularan. Analisis multivariat menunjukkan variabel ini memiliki hubungan signifikan $(p<0,05)$. Pekerjaaan sebagai petani memiliki nilai $\mathrm{OR}=2,8 ; 95 \%$ $\mathrm{CI}=1,22-6,48$ artinya responden yang memiliki pekerjaan sebagai petani mempunyai risiko sebesar 2,8 kali lebih besar untuk terjadi penyakit Schistosomiasis japonicum, dibandingkan pada responden yang memiliki pekerjaan selain petani.

Selain itu penelitian yang pernah dilakukan oleh Harianto menjelaskan bahwa memiliki pekerjaan sebagai petani berisiko terhadap kejadian Schistosomiasis japonicum pekerjaan $(\mathrm{OR}=2,9 ; 95 \% \mathrm{CI}=1,52-5,65){ }^{12}$

Petani merupakan pekerja yang berisiko untuk terinfeksi Schistosomiasis japonicum karena petani pada saat melakukan pekerjaan di sawah berada dalam lingkungan yang berair dan berlumpur dengan keadaan kaki yang telanjang tanpa menggunakan pelindung, keadaan tersebut mempermudah terjadinya kontak langsung antara kulit kaki dengan tanah atau air yang mengandung serkaria parasit Schistosomiasis japonicum, kebiasaan yang dilakukan petani di daerah Taman Nasional 
Lore-Lindu pada saat selesai bekerja mereka mencuci tangan dan kaki di parit yang ada disekitar persawahan, air tersebut berasal dari fokus keong Oncomelania hupensisi linduensis.

Kebiasaan mandi atau mencuci di danau atau di air sungai berhubungan dengan kejadian Schistosomiasis japonicum $(p=0,016)$ dan nilai $\mathrm{OR}=2,7 ; 95 \% \mathrm{CI}=1,21-6,39$. Artinya masyarakat yang memiliki kebiasaan mandi dan mencuci di air sungai atau di air danau memiliki risiko sebesar 2,7 kali lebih besar untuk terjadinya Schistosomiasis japonicum di bandingkan dengan masyarakat yang memiliki kebiasaan mandi atau mencuci selain di danau atau di sungai, tidak berisiko di kamar mandi menggunakan air dari perpipaan.

Penelitian ini sejalan dengan penelitian yang dilakukan oleh Rosmini (2010) menjelaskan bahwa kebiasaan mandi di air sungai atau air danau berhubungan dengan kejadian Schistosomiasis japonicum dengan nilai $\mathrm{OR}=16,1$ kali lebih besar dibandingkan dengan orang yang mandi atau mencuci di kamar mandi mengunaka air dari perpipaan. ${ }^{13}$

Semakin banyak orang yang mandi dan mencuci di air sungai atau air danau semakin besar peluang terjadinya infeksi Schistosomiasis japonicum, karena terjadi kontak langsung dengan air sungai, yang terkontaminasi dengan serkaria parasit Schistosomiasis japonicum melalui aktifitas membersihkan diri, mandi atau mencuci di sungai atau di danau.

Jamban keluarga adalah suatu fasilitas pembuangan tinja yang efektif untuk memutuskan mata rantai penularan penyakit, masyarakat masih banyak yang memanfaatkan air sungai, air danau, semak-semak untuk membuang kotoran, bagi penderita Schistosomiasis japonicum yang tidak memanfaatkan jamban untuk buang air besar, akan menyebarkan telur cacing yang keluar bersama tinja menyebar bersama aliran air, kondisi ini lebih potensi jika menemukan Host perantara berupa keong Oncomelania hupensisi linduensis, dengan membuang tinja di sembarang tempat akan menyebabkan penyebaran telur lebih meluas, dan memungkinkan infeksi baru pada orang lain yang sehat. Analisis multivariat menunjukkan variabel ini memiliki hubungan yang signifikan $(p=0,007)$ dan nilai $\mathrm{OR}=3,0$ pada 95\% CI=1,36-6,86. Artinya masyarakat yang tidak buang air besar di jamban memiliki risiko 3,0 kali lebih besar untuk terjadinya Schistosomiasis japonicum di bandingkan dengan masyarakat yang memanfaatkan jamban keluarga sebagai tempat buang air besar.

Penelitian yang dilakukan oleh Anas S. (2002) yang menjelaskan bahwa buang air besar selain di jamban keluarga memiliki risiko 7,9 kali lebih besar terhadap kejadian Schistosomiasis japonicum dengan nilai $p=$ 0,01 OR=7,9 dan CI95\% = 3,10-20,13).)

Orang yang terbiasa buang air besar tidak di jamban yaitu di air sungai, pada saat mereka buanga air besar lebih mudah dibandingkan di jamban, karena pada saat buang air besar di sungai atau di danau bagian tubuh mereka yang terendam oleh air sungai, kondisi seperti ini menambah besar risiko terinfeksi serkaria pada saat bagian tubuh mereka terendam air yang tidak terlindungi, hal tersebut mempermuda serkaria masuk dari pori-pori kulit yang tidak terlindungi.

Penggunaan alat pelindung diri seperti sepatu jenggel boot saat bekerja di persawahan suatu tindakan yang aman, sepatu jenggel boot melindunggi kaki terkontaminasi langsung dengan air yang mengandung serkaria ataupun tempat fokus keong perantara Schistosomiasis japonicum. Tidak menggunakan sepatu jenggel boot pada saat bekerja di sawah pada analisis multivariat menunjukkan hubungan yang signifikan terhadap kejadian Schistosomiasis $(p=0,001)$ dan nilai $\mathrm{OR}=4,6$ pada $95 \%$ $\mathrm{CI}=1,99-10,58$. Artinya masyarakat yang tidak 
menggunakan alat pelindung diri seperti sandal atau sepatu jenggel boot saat melakukan aktifitas di luar rumah atau bekerja di sawah memiliki risiko sebesar 4,6 kali lebih besar untuk terjadinya Schistosomiasis japonicum di bandingkan dengan orang yang menggunakan alat pelindung diri saat bekerja di sawah, berdasarka temuan dilapangan telah menjadi kebiasaan jika berkerja di persawahan tidak menggunakan sepatu jenggel boot.

Hasil penelitian ini tidak berbeda dengan penelitian yang dilakukan oleh Harianto (2006) yang menjelaskan bahwa kebiasaan tidak menggunakan alat pelindung diri seperti sepatu jenggel boot berisiko terhadap kejadian Schistosomiasis japonicum sebesar 2,2 kali lebih besar dibandingkan dengan responden yang menggunakan alat pelindung diri pada saat pergi bekerja di sawah. ${ }^{14}$

Melewati daerah fokus menjadi dua yaitu: daerah fokus alami yaitu daerah becak sekitar rembesan air di pingiran hutan dan fokus di dalam hutan, sedangkan fokus buatan manusia seperti: daerah becek sekitar kebun, padang rumput bekas sawah yang tidak diolah, maupun rawa bekas sawah, tempat tersebut orang sering melewati pada saat menuju untuk bekerja di persawahan.

Hasil penelitian ini analisis multivariat menunjukkan bahwa variabel bepergian ke daerah fokus keong berhubungan dengan kejadian Schistosomiasis japonicum $(p=0,008)$ dan nilai $\mathrm{OR}=3,1$ pada $95 \% \mathrm{CI}=1,34-7,41$. Artinya orang yang melewati daerah fokus keong saat pergi bekerja di sawah memiliki risiko sebesar 3,1 kali lebih besar untuk terjadinya Schistosomiasis japonicum di bandingkan dengan orang ke sawah yang tidak melewati daerah fokus keong.

Tempat fokus seperti persawahan, rawarawa, padang rumput yang berair, air tergenag, dan pingiran parit di antara persawahan, tempat-tempat inilah yang sering di lewati oleh masyarakat yang hendak bekerja menuju persawahan, mereka mengetahui daerah yang di lewati merupakan daerah fokus aktif, akan tetapi mereka tetap melewatinya karena tidak ada pilihan lain, sebab jalan tersebut yang paling mudah dan dekat untuk sampai di sawah mereka, dengan seringnya kontak dengan tempat-tempat fokus memungkinkan masuknya serkaria di dalam tubuh yang menyebabkan orang tersebut menderita Schistisomiasis japonicum.

Lahan pertanian yang berupa bekas sawah yang ditinggalkan, tidak digarap dalam waktu yang lama dapat menyebabkan lahan pertanian menjadi rawa-rawa, genagan air, ditumbuhi rerumputan dan semak-semak. Hal ini salah satu terkait dengan distribusi keong yang terseber luas di Kawasan Taman Nasional Lore-Lindu dan mobilitas masyarakat Taman Nasional Lore-Lindu dalam hubungan dengan mata pencarian mereka menjadi salah satu faktor risiko penularan Schistosomiasis japonicum terus meningkat tiap tahun. Habitat keong Oncomelani hupensis linduensis daerah genagan air jernih dengan bayak rumput atau daun-dedaunan jatuh, pada area persawahan, keong bayak ditemukan pada tempat tersebut sawah yang tidak diolah atau pada saluran irigasi dengan air tergenang dan banyak rerumputan. ${ }^{15}$

Berdasarkan penelitian $(p=0,001)$ dan nilai $\mathrm{OR}=5,2 ; 95 \% \mathrm{CI}=2,25-12,09$, kepemilikan tata guna lahan pertanian memiliki risiko $5,2 \mathrm{kali}$ lebih besar, dibandingkan mereka yang tidak memiliki lahan pertanian yang tidak diolah. Perubahan lahan cenderung menjadi masalah bersifat negatif di dalam sektor pertanian, akan tetapi masih banyak lahan pertanian yang dialih fungsikan karena tekanan ekonomi pada masa krisis ekonomi atau rendahnya hasil jual di bidang pertanian menyebabkan banyak petani yang tidak mengolah lahannya.

Lahan yang tidak di tanami padi dalam jangka waktu yang lama, lahan tersebut ditumbuhi rerumputan dan tanah menjadi berlumpur, dari lahan yang tidak dikelola 
menjadi tempat memelihara hewan ternak, seperti kerbau, sapi, babi dan kuda. Pemilik lahan setiap hari pergi berkunjung ke lahan tersebut untuk memberikan makan ternak, pada saat terjadi penularan Schistosomiasis japonikum pada saat orang tersebut masuk ke lahan dan tidak menggunakan sepatu jenggel boot, mencari rumput di lahan tersebut dan pada saat lahan tersebut diolah kembali menjadi persawahan.

Keterbatasan penelitian terletak pada desain penelitian ini bersifat retrospektif (casecontrol) sehingga recall bias sangat mungkin terjadi. Penelitian ini belum dapat didukung dengan pemeriksaan tinja secara langsung di laboratorium Schistosomiasis japonicum. Faktor risiko lain seperti status gizi, suhu udara, kondisi sinar matahari, kondisi hujan, keberadaan tikus, $\mathrm{PH}$ air dan $\mathrm{PH}$ tanah, yang tercantum dalam kerangka teori tidak diteliti karena keterbatasan waktu dan dana.

\section{Kesimpulan}

Berdasarkan hasil penelitian dapat disimpulkan bahwa variabel yang terbukti sebagai faktor risiko kejadian Schistosomiasis japonicum pada masyarakat pekerjaan sebagai petani, kebiasaan mandi atau mencuci di air sungai atau di air danau, tidak buang air besar di jamban keluarga, tidak menggunakan alat pelindung diri seperti sepatu jenggel boot saat bekerja di sawah, melewati daerah fokus keong, memiliki tata guna lahan pertanian tidak di kelolah, dari 6 faktor risiko tersebut secara bersamaan sebesar 98,52\%. Variabel yang tidak terbukti sebagai faktor risiko kejadian Schistosomiasis yaitu: tingkat pendidikana rendah <SMP, menjadi anggota dalam budaya mapalus/gotong royong di bidang pertanian, pemanfaatan program kesehatan, dan memelihara hewan ternak.

\section{Saran}

Diharapkan kepada seluruh masyarakat yang tinggal di Taman Nasional Lore-Lindu Kabupaten Sigi Provinsi Sulawesi Tengah yaitu:.

1. Mengikuti program kesehatan seperti pemeriksaan tinja secara rutin tiap 6 bulan sekali, agar masyarakat mengetahui secara dini apakah mereka menderita Schistosomiasis japonicum atau tidak.

2. Masyarakat disarankan agar ikut serta dalam pemberantasan fokus keong, mengikuti kegiatan penyuluhan,

3. Masyarakat yang bekerja sebagai petani, pada saat melakukan kegiatan di luar rumah, bekerja di persawahan dan melewati daerah fokus disarankan untuk menggunakan alat pelindung diri seperti sandal atau sepatu jenggel boot agar kaki terhindar dari air yang terkontaminasi oleh serkaria.

4. Masyarakat yang memiliki kebiasaan mandi/mencuci di air sungai atau air danau disarankan menggunakan sabun anti bakteri, hal ini dapat memperkecil risiko masuknya serkaria dalam pori-pori kulit, kemudian saat mandi di air sungai dan air danau di sarankan tidak melakukan kegiatan lain seperti: menyelam, berenang dan memancing ikan.

5. Masyarakat yang memiliki lahan pertanian yang tidak dikelolah dalam jangka waktu yang lama, disarankan lahan perswahan yang dimiliki segera dikelolah setiap tahun minimal 2 kali dalam setahun atau lahan tersebut dikeringkan, disarankan jika lahan tersebut menjadi tempat melihara hewan ternak, saat berkunjung menggunakan alas kaki atau sepatu jenggel boot saat beraktifitas di lahan tersebut.

\section{Daftar Pustaka}

1. Mahmoud AA. 2001. Schistosomiasis. Volume 3. Geoffrey Pasvol and Stephen L Hoffman, Editor. London; 2001. 7-8 p.

2. Garcia LS. 1996. David AB. Diasnostik Parasitologi Kedokteran. Jakarta; Penerbit 
Buku Kedokteran. ECG. 256-258 p.

3. Gordon CC. 2009. Menson's Tropical Diseases. Twenty-Second ed.: Saunders Elsevier; Medik Book Store; 207--238 p.

4. Bernandus S. 2007. Helminthologi Kedokteran. Jakarta; Prestasi Pustaka, 329-347 p.

5. Mujiyanto, Jastal. 2014. Pemanfaatan Pengindraan Jauh dan Sistem Informasi Geografis Dalam Indentifikasi Fokus Baru Schistosomiasis di Dataran Tinggi Bada Kabupaten Poso Provinsi Sulawesi. Seminar Nasional Penginderaan Jauh. 13 (2):739-732.

6. Garjito TA. 2014. Distribusi Habitas Oncomelania Hupensisi Linduensis Keong Perantara Schistosomiasis Japonicum Di Dataran Tinggi Lindu Kabupaten Sigi Sulawesi Tengah. Jurnal Peneliti Kesehat. Bul, 42(3):139-52.

7. Dinkes Provinsi Sulawesi Tengah. 2014. Profil Dinas Kesehatan Provinsi Sulawesi Tengah.. 3-10 p.

8. Dinkes Kabupaten Sigi. 2015. Profil Dinas Kesehatan Kabupaten Sigi..12-16 p.

9. Soedarto. 2011. Buku Ajar Parasitologi Kedokteran. Jakarta; Sagung Seto,.175$198 \mathrm{p}$.

10. Armenian HK. The Case Control Method Desain and Aplication. New York: Oxford University Press; 2009.

11. Sastroasmoro S. 2014. Dasar-Dasar Metodologi Penelitian Klinis. Jakarta: Sagung Seto; 49-98 p.

12. Hariyanto M. 2006. Pemanfaatan Air Sungai dan Infeksi Schistosoma Japonicum di Napu Poso Sulawesi Tengah. Jurnal Kesehat Masy Nas. 31 (1): 219-25.

13. Rosmini. 2010. Beberapa Faktor Yang Berhubungan Dengan Penularan Schistosomiasis Japanicum Di Dataran Tinggi Napu Kabupaten Poso Sulawesi Tengah. Jurnal peneliti Kesehat. 38 (2): 131-9.
14. Simbadu A. 2002. Pengaruh Pekerjaan, Status Gizi, Pemanfaatan Jamban Keluarga dan Pemanfaatan Sarana Air Bersih Terhadap Terinfeksi Schistosomiasis Japonicum Pasca-Terapi di Dataran Tinggi Napu Kabupaten Poso Propinsi Sulawesi Tengah. Surabaya; Universitas Airlangga. Tesis

15. Hafsah. 2013. Karakteristik Habitat dan Morfologi Siput Ongcomelania Hupensis Linduensis Sebagai Hewan Reservoir Dalam Penularan Schistosomiasis Pada Manusia dan Ternak di Taman Nasional Lore Lindu. Jurnal Mns dan Lingkung. 20 (2): 144-52. 